\title{
The assessment of pharmacists' willingness to join a pharmaceutical care pilot project in Poland
}

\author{
Daria Kulpa ${ }^{1}$, Urszula Religioni, $\mathrm{PhD}^{2}$, Jerzy Krysinski, Prof. ${ }^{1}$, Piotr Merks, $\mathrm{PhD}^{1,3}$ \\ ${ }^{1}$ Department of Pharmaceutical Technology, Faculty of Pharmacy, Collegium Medicum in Bydgoszcz, Poland \\ ${ }^{2}$ Collegium of Business Administration, Warsaw School of Economics, Poland \\ ${ }^{3}$ Faculty of Medicine, Collegium Medicum, Cardinal Stefan Wyszyński University, Warsaw, Poland \\ p.merks@uksw.edu.pl \\ telephone: +48602101979
}

Abstract. The primary objective of this paper is to determine the willingness of pharmacists to take part in a pilot project of pharmaceutical care, and to indicate the factors influencing these decisions.

Methods. The study was conducted using an anonymous online questionnaire. 123 Polish pharmacy staff members participated in the study.

Results. The vast majority of the pharmacists $(84 \%)$ wanted to join the pharmaceutical care pilot project. The main benefits of pharmaceutical care perceived by the respondents included a reduced number of medication errors, an increase in the prestige of the profession, and job satisfaction. Those who noticed more benefits from pharmaceutical care expressed more willingness to implement it $(\mathbf{p}<0.001)$.

Conclusions. Pharmaceutical care, focused on improving the quality of pharmacotherapy, is essential for public health. Polish pharmacists are ready to implement pharmaceutical care in their pharmacies. They indicate the provision of training sessions in this area as a key element of the implementation of these services.

Key words: pharmaceutical care, Poland, pharmacists, community pharmacy

\section{Introduction}

According to the definition of the International Pharmaceutical Federation (FIP), pharmaceutical care is the responsible provision of drug therapy for the purpose of achieving definite outcomes that improve a patient's quality of life. These outcomes are: curing a disease; elimination or reduction of patient symptomatology; arresting or slowing a disease process; preventing a disease or symptomatology [1]. A similar definition was formulated by the American Society of Health-System Pharmacists, which indicates that pharmaceutical care is the direct responsible provision of medication-related care for the purpose of achieving definite outcomes that improve a patient's quality of life [2].

Pharmaceutical care comprises cooperation between the pharmacist, the patient and other health care professionals in developing, implementing and monitoring a therapeutic medication plan that is intended to bring specific therapeutic outcomes for the patient. It includes three major functions:

1. identifying potential and real medication-related problems,

2. solving real medication-related problems,

3. preventing potential medication-related problems [1].

Pharmaceutical care is an integral part of the health care system [2]. The work of pharmacists ensures safe, efficacious and rational use of medications [3], and thus has a direct impact on improvements in patient health and wellbeing [4]. Implementation of a pharmaceutical care program delivers a number of benefits. First of all, direct contact with a patient and establishing trust allow a pharmacist to influence patient behavior to improve adherence. According to the World Health Organization (WHO), adherence is "the extent to which a person's behavior - taking medication, following a diet, and/or executing lifestyle changes - corresponds with the agreed recommendations" [5]. Non-adherence can result in a higher incidence of deaths, as well as increased costs to the health care system. [6]. Numerous studies have confirmed the effectiveness of a pharmacist's intervention, particularly in chronic patients [7]. In patients under pharmaceutical care, improved adherence, greater knowledge about the disease and better examination results are observed [8,9,10,11]. Pharmacists' help in the proper use of OTC medications, especially in older patients (due to the high risk of polypharmacy and the resulting health consequences) is of great significance [12]. 
Currently in Poland there are about 13,000 community pharmacies and 1,300 smaller pharmacy outlets, with 27,000 masters of pharmacy and 33,300 pharmaceutical technicians [13]. Most retail trade of medications in Poland is through community pharmacies. Pharmacy outlets carry a much smaller assortment and can only be established in rural areas if there is no community pharmacy there. Pharmacy outlets do not need to employ a pharmacist, and thus no pharmaceutical care can be provided. Despite many years of discussions on conducting pharmaceutical care in Poland, such activities are not generally conducted or financed from the state budget. Currently in Poland there are two independent pharmaceutical care pilot programs under the auspices of the Polish Pharmaceutical Chamber [14].

The primary objective of this paper is to determine the level of willingness of pharmacists to take part in a pharmaceutical care pilot project, and to indicate the factors influencing these decisions. Identification of the benefits and barriers to pharmaceutical care perceived by the pharmacists was also important.

\section{Material and methods}

The study was conducted in the form of an anonymous online questionnaire. The questionnaire was addressed to pharmacists working in pharmacies. Any willing pharmacist could take part in the study. The questionnaire contained 12 single or multiple choice questions, or open-ended questions. The questionnaires were accompanied by information about the objectives of the study along with a written request to complete them.

Comparisons of the results obtained from the study were made using MS Excel 2016 and Statistica 13. The assumed level of statistical significance was $\mathrm{p}<0.05$.

123 employees of pharmacies took part in the study. The average age of the respondents was 34.14 years, with the youngest 26 years old, and the oldest 65 years old. $54 \%$ of respondents worked in chain pharmacies, and $46 \%$ in private pharmacies.

\section{Results}

Of all the respondents, $84 \%$ were willing to join the pharmaceutical care pilot project. This willingness was not related to the respondents' age or workplace $(p>0.05)$. The respondents were asked about their knowledge of mobile apps supporting pharmaceutical care available in the Polish market, e.g. the Patient Access or Refer the Patient. Those who knew the the Patient Access app were more willing to join the pilot project $(\mathrm{p}=0.032)$.

One objective of the study was pharmacist identification of the benefits and barriers to implementation of pharmaceutical care. The most frequently mentioned benefits for patients in terms of implementation of the pharmaceutical care pilot project were fewer medication errors $(78.9 \%)$, reduced adverse reactions $(69.1 \%)$, and better understanding by the patient of the purpose of the medications (64.2\%). Among the less frequently indicated responses were easy access to specialist advice (50.4\%) and the reduced number of deaths caused by improper use of medications $(38.2 \%)$ - Figure 1 .

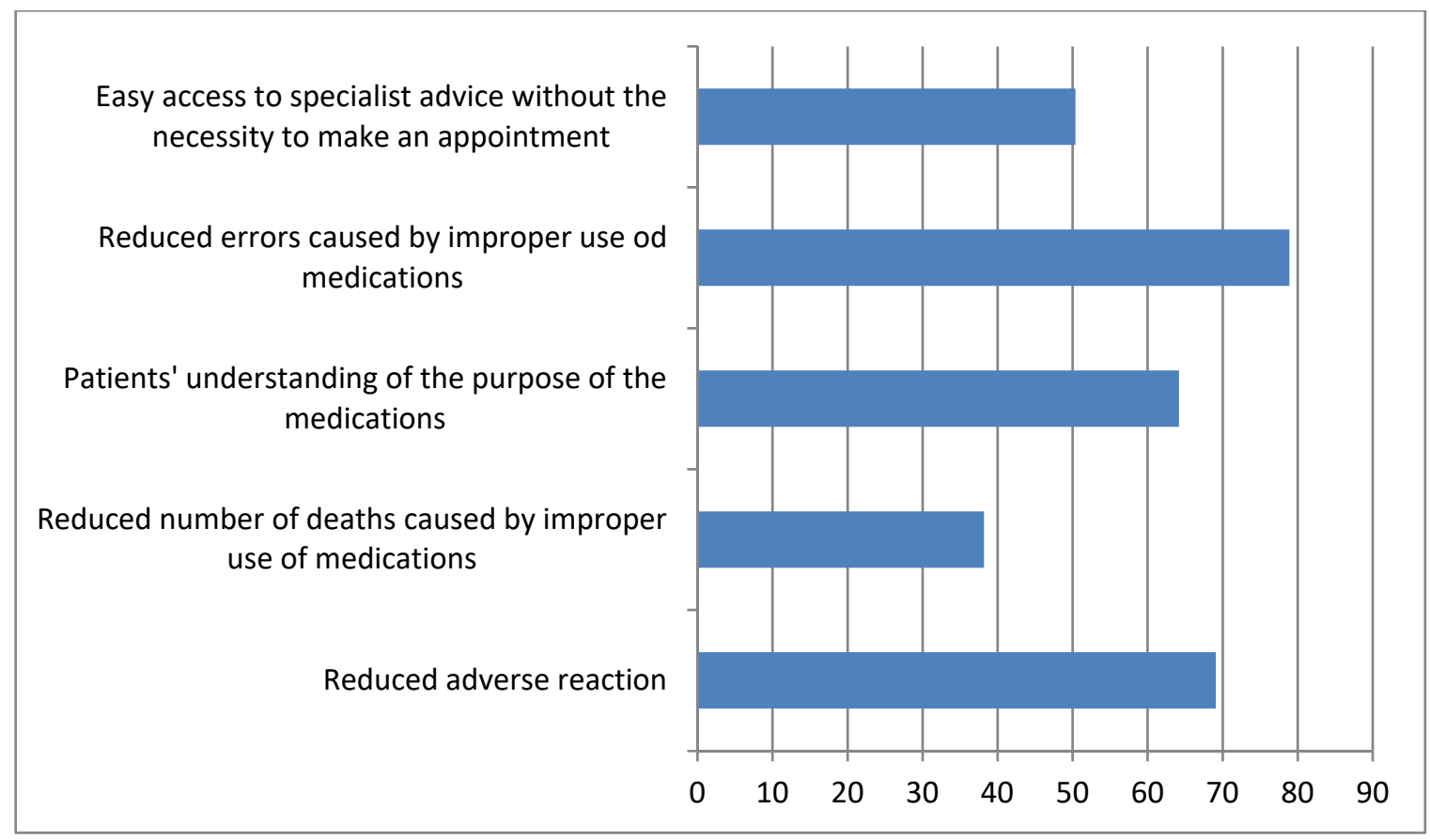

Figure 1. Patient benefits of the implementation of the pharmaceutical care pilot project, as perceived by pharmacists (\% of responses) 
As far as benefits to pharmacist by providing pharmaceutical care are concerned, the respondents indicated an increase in the prestige of the profession $(78.0 \%)$ and in job satisfaction $(69.1 \%)$. A less frequent response was improved relationships with patients $(57.7 \%)$. All the benefits indicated by the pharmacists are presented in Figure 2.

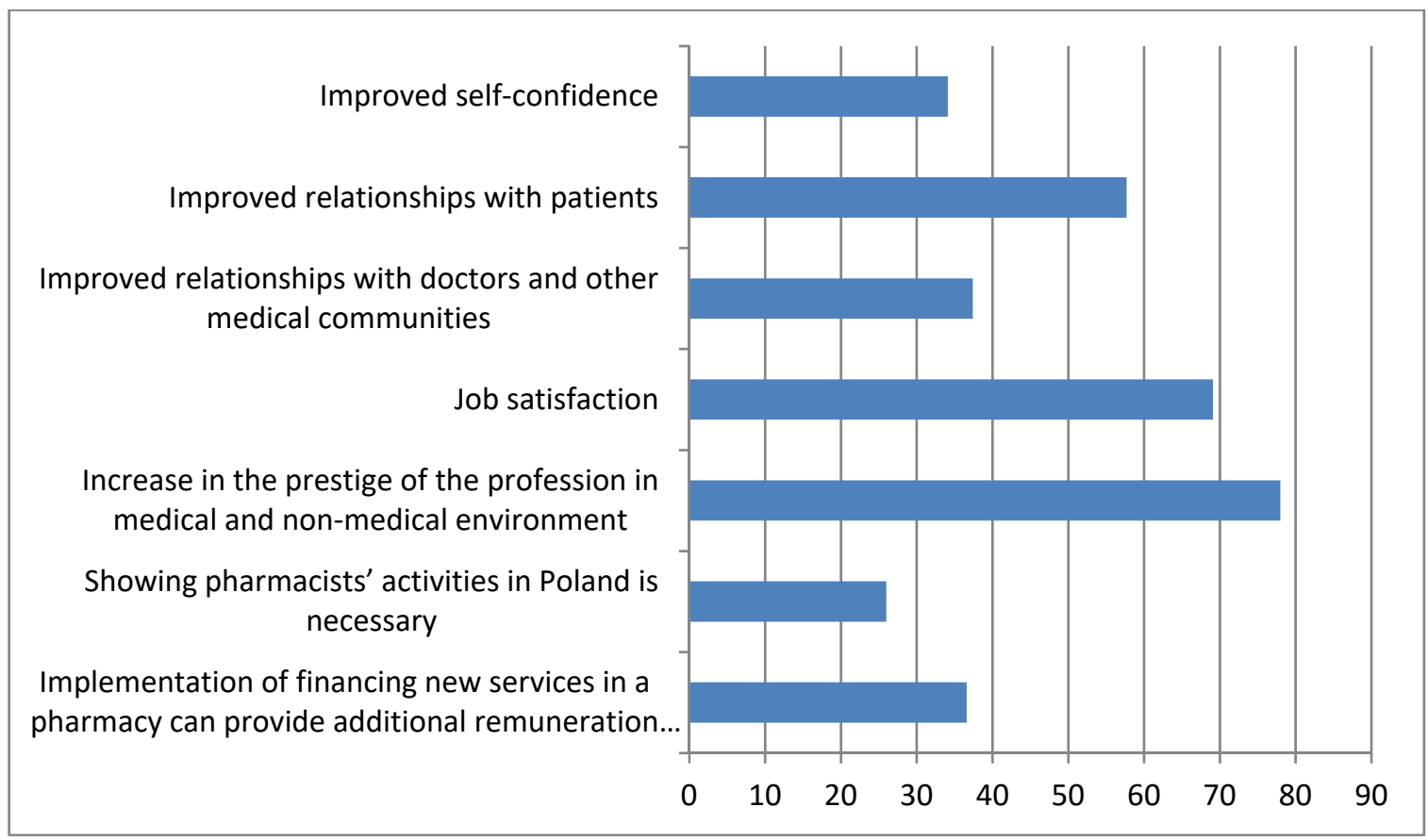

Figure 2. Benefits to pharmacists by providing pharmaceutical care ( $\%$ of responses)

The main barriers to the implementation of pharmaceutical care indicated by the respondents were the lack of time $(61.8 \%)$, and the lack of adequate space or training (55.3\% and 50.4\%, respectively). The identified barriers are presented in Figure 3.

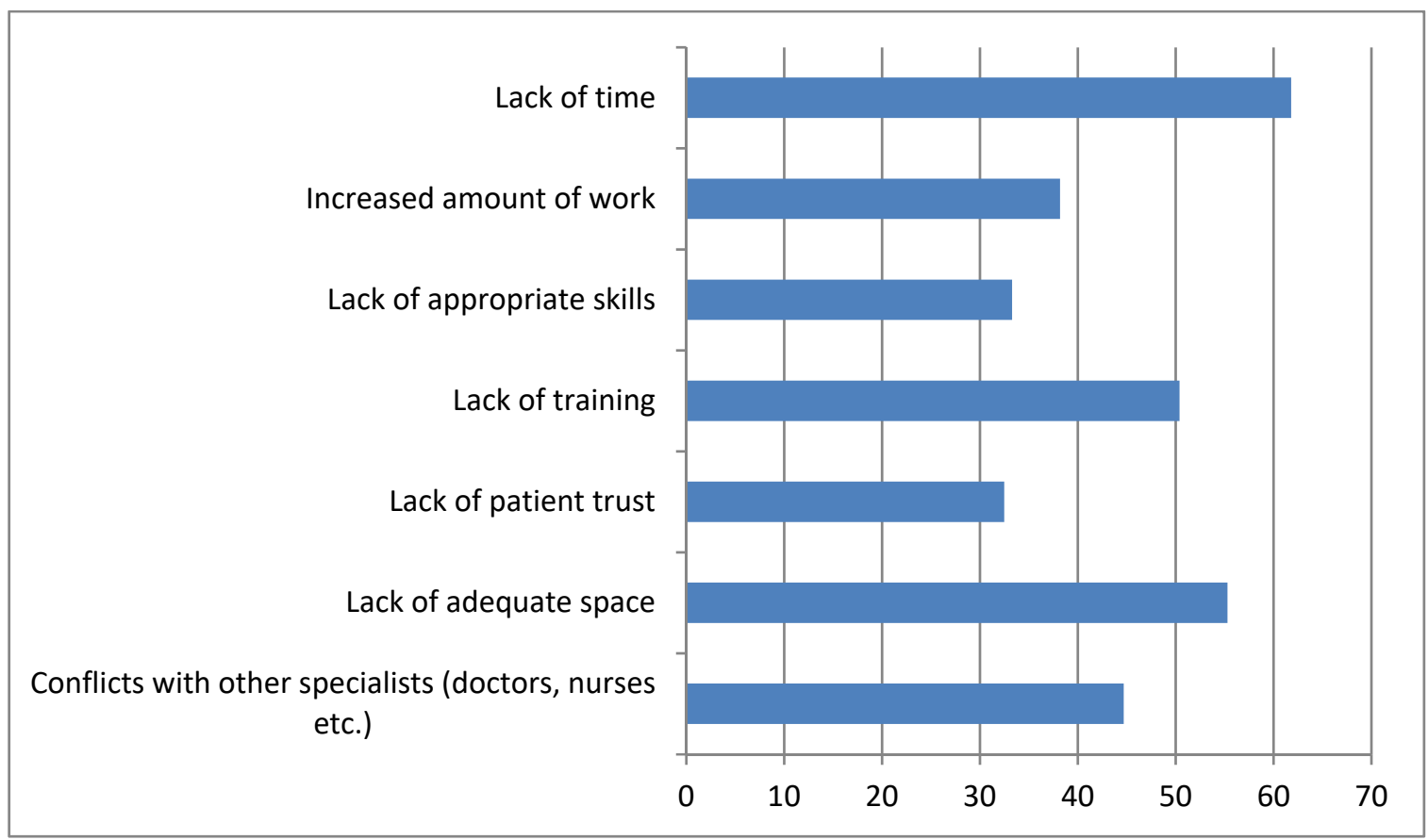

Figure 3. Barriers in performing pharmaceutical care, as perceived by pharmacists (\% of responses)

The most common elements required to implement pharmaceutical care services reported by the respondents were appropriate training $(81.3 \%)$ and providing appropriate space for a consultation room (69.9\%). Less frequent responses included appropriate software, validated tools for communication with patients, and consent of state authorities (Figure 4). 


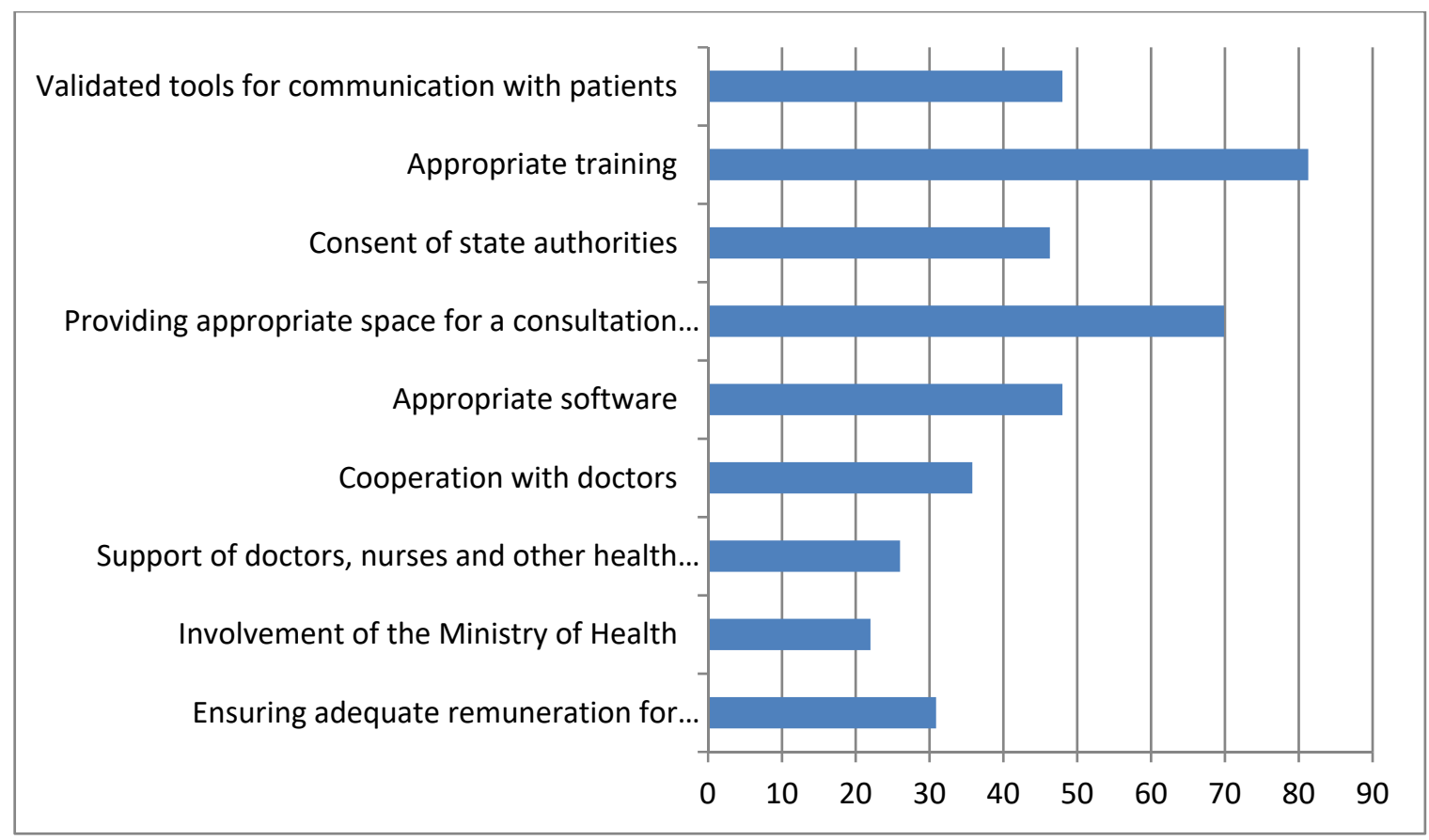

Figure 4. Elements required to implement pharmaceutical care services, as perceived by pharmacists (\% of responses)

The number of benefits and barriers to pharmaceutical care indicated by the pharmacists in relation to the readiness of pharmacists to implement pharmaceutical care in pharmacies was analyzed (Table 1). The questions concerning the benefits and barriers were multiple choice questions, and the maximum allowed number of responses was 7 .

Table 1. Descriptive and statistical analysis of the distribution of the number of benefits and barriers to the implementation of the pharmaceutical care pilot project in groups of persons willing and unwilling to participate in the pharmaceutical care pilot project

\begin{tabular}{|c|c|c|c|c|c|c|c|c|c|c|}
\hline $\begin{array}{c}\text { Willingness to } \\
\text { participate }\end{array}$ & $\mathrm{n}$ & $\bar{x}$ & SD & Min. & $\mathrm{Q}_{1}$ & $\mathrm{Me}$ & $\mathrm{Q}_{3}$ & Max. & $\begin{array}{c}\text { Result of } \\
\text { Mann- } \\
\text { WhitneyU } \\
\text { test }\end{array}$ & $\mathrm{p}$ value \\
\hline \multicolumn{11}{|c|}{ Patient benefits of the implementation of the pharmaceutical care pilot project } \\
\hline No & 20 & 1.40 & 0.94 & 0 & 1 & 1 & 1.5 & 4 & \multirow{2}{*}{-5.690} & \multirow{2}{*}{$<0.001$} \\
\hline Yes & 103 & 3.53 & 1.30 & 1 & 3 & 4 & 5 & 6 & & \\
\hline \multicolumn{11}{|c|}{ Benefits to pharmacists by providing pharmaceutical care } \\
\hline No & 20 & 1.40 & 1.27 & 0 & 1 & 1 & 1.5 & 6 & \multirow{2}{*}{-6.001} & \multirow{2}{*}{$<0.001$} \\
\hline Yes & 103 & 4.36 & 1.66 & 1 & 3 & 4 & 6 & 8 & & \\
\hline \multicolumn{11}{|c|}{ Barriers to the implementation of pharmaceutical care } \\
\hline No & 20 & 3.95 & 1.76 & 1 & 3 & 4 & 5 & 7 & \multirow{2}{*}{1.437} & \multirow{2}{*}{0.151} \\
\hline Yes & 103 & 3.31 & 1.75 & 0 & 2 & 3 & 4 & 7 & & \\
\hline
\end{tabular}

Those pharmacists who were willing to participate in the pilot program were significantly more likely to indicate a greater number of benefits for patients and pharmacists (in both cases $\mathrm{p}<0.001$ ). In the first parameter the mean score was $3.53 \pm 1.30$, while in the other $4.36 \pm 1.66$. Comparing the results in relation to those respondents who did not want to take part in such a project, the differences were about 2 points in the first case (mean $1.40 \pm 1.30$ ) and about 3 points in the other (mean $1.40 \pm 1.27$ ). 
Nevertheless, the number of perceived barriers did not affect the willingness to implement pharmaceutical care. In the group not interested in the implementation of the pharmaceutical care pilot project, the average number of indications regarding the occurrence of barriers was $3.95 \pm 1.76$. In the other group the result was $3.31 \pm 1.75$ $(\mathrm{p}>0.05)$.

\section{Discussion}

This study is the first broad view of the issue of pharmaceutical care in Poland. The last study of this type was conducted among pharmacists in one of the regions and concerned slightly different aspects of pharmaceutical care [15].

In this study, the vast majority of respondents $(84 \%)$ showed a willingness to join the pharmaceutical care pilot project. This proves that the pharmaceutical community notices the need to develop and improve the quality of pharmaceutical services in Poland. Most of the obtained results have been confirmed in earlier studies. The benefits to the pharmacists related to the implementation of the pharmaceutical care project indicated by the majority of the respondents (e.g. increased prestige of the profession, job satisfaction) are similar to other Polish studies [16]. In literature, one of the main benefits of the implementation of pharmaceutical care is improved adherence. It is estimated that $30-50 \%$ of patients do not follow medical recommendations, which significantly increases the risk of death [6]. This is particularly important in chronic patients. Here, low adherence may result from various reasons, e.g. no symptoms, long-term treatment, side effects, complicated treatment regimens, lack of knowledge about the purpose of pharmacotherapy, lack of awareness of the risk, and the cost of the medications [17]. Improved adherence in chronic patients, in turn, brings a lot of benefits thanks to support of pharmacists. For example, in a group of patients with asthma, the frequency of acute attacks and nocturnal symptoms decreased and the quality of life of these patients improved, as evidenced by less sick leave $[9,18]$. The pharmacist's intervention was also beneficial for patients with other chronic diseases, e.g. diabetes (the concentration of HbA1c and fasting blood sugar levels significantly decreased), as well as hypertension (the pharmacist's assistance resulted in a reduction of blood pressure) $[8,10]$. Pharmaceutical care of patients with breast and ovarian cancer contributed to a significant reduction in adverse effects resulting from the therapies [11].

Monitoring patient pharmacotherapy by a pharmacist makes it possible to identify, solve and prevent problems related to pharmacological treatment, such as drug interactions or side effects. Such practices limit or reduce mortality and morbidity rates in society, and may also lower the costs of health care [8]. A study carried out in Pennsylvania showed a significant reduction in annual healthcare expenditure per patient among patients taking statins and patients with diabetes receiving pharmaceutical care. This study showed that the intervention envisaged by a pharmacist is a cost-effective tool that can be used in pharmacies and health care facilities [19].

It is also of great significance to support pharmacists in the use OTC medications by patients, which, despite their high popularity, are usually used by patients without consulting their doctors. Self-treatment brings measurable benefits to the health care system - it lowers the costs of treatment through a better use of the potential of pharmacists, and rationalization of visits to primary care physicians. Despite these benefits, this process is also associated with some risk caused by improper diagnosis, exposure to adverse effects or dangerous interactions, as well as "masking" of symptoms of dangerous diseases [20]. Studies indicate that patients often do not use OTC medications properly. The problems concern mainly wrong dosage and/or taking medications according to improper dosing regimens [12].

The main barrier in providing pharmaceutical care services most often indicated by the respondents in this study is the lack of time, which is also confirmed in the studies by Skowron A. and Rybka B. [21]. On the other hand, in the studies published by Świeczkowski D. et al., the conflict between a doctor and a pharmacist was indicated as the main barrier [15]. In the present study, that response was stated by fewer than half of respondents $(44.7 \%)$ as a barrier to the implementation of pharmaceutical services.

In the question about the elements required to implement pharmaceutical care, the respondents most often reported appropriate training sessions and ensuring a suitable place to conduct consultations. Another condition indicated in literature was having appropriate IT tools [22]. Projects supporting pharmaceutical care have been conducted in Poland for many years. The first was EM-PMR [23], a pilot program for patients with chronic diseases [24]. Also, platforms such as The Patient Access [25], Refer the Patient [26] and Healthy Heart Service (including the care of patients after myocardial infarction) [27], have been developed. Pharmacists in Poland enjoy patient confidence and are perceived as authorities on medications. More than $80 \%$ of patients expect pharmacists' advice on drugs or minor health problems, and more than half of them are in favor of introducing pharmaceutical care into pharmacies [28]. An important element of the implementation of pharmaceutical care in Poland is also pharmacy employees' interest in this service. Both pharmacists and pharmaceutical technicians will have to go through a long training phase to prepare for performing pharmaceutical care. The implementation of this service involves reorganization of work in pharmacies - the auxiliary personnel (technicians) will have to take over some of pharmacists' duties related to filling prescriptions and dispensing medicines to enable pharmacists to devote their time to patients [29]. The issue of reconstruction of pharmacies to create so-called consultation rooms is also 
crucial [30]. There is currently no obligation for such a room to be located in a pharmacy, according to the Regulation of the Minister of Health on the list of rooms included in the basic and auxiliary area of a pharmacy [31].

The above mentioned arguments show that the implementation of pharmaceutical care in Poland has been supported by the doctors as well as by those most interested, i.e. the patients. Unfortunately, this is going to be a long-term process, as it still requires many changes, both legal and organizational.

In comparing the presented study results, it can be stated that the data obtained are very similar, which shows that the problems related to the implementation of pharmaceutical care services have not changed and still exist. The willingness of pharmacists to make changes seems very important, despite the difficulties they notice. This gives a chance to improve the situation in Polish pharmacies and to introduce new services. The implementation of pharmaceutical care, although connected with many changes, looks to be beneficial for both pharmacists and patients.

\section{Limitations}

The small study group (123 respondents) may be a limitation of this study. The online questionnaire turned out to be an effective and helpful solution - the questionnaire was placed on an Internet platform, and links to it were placed on platforms for pharmacists and pharmaceutical industry websites, such as pictorex.pl or the Trade Union for Pharmacy Workers. It should be noted, however, that the data collected in this way is underestimated. The reason for this is the significantly smaller share of older respondents who are not as active in a virtual environment as young people.

\section{Conclusions}

The majority of pharmacists in Poland, regardless of age or place of work, are ready to implement the pharmaceutical care pilot project. Those respondents who want to take part in this program indicated significantly more benefits of pharmaceutical care for both patients and pharmacists. The respondents reported training sessions as the main element required to implement pharmaceutical care.

In order to effectively implement pharmaceutical care in Poland, it is necessary to reinforce this idea among patients and other professional groups, thus emphasizing the importance of the role of pharmacists in the health care system. A relatively large barrier to the implementation of pharmaceutical care services in Poland is incomplete computerization of the health care system, or the lack of precise legal acts regulating this area. Thus, action at a sector-wide level is necessary to implement pharmaceutical care. The implementation of pharmaceutical care will result in a significant improvement in patient health outcomes, contributing to significant savings in the health sector. Pharmaceutical care, focused on improving the quality and efficiency of patient treatment, is an essential part of public health support.

\section{Acknowledgements and Funding}

This research received no specific grant from any funding agency in the public, commercial, or not-for-profit sectors.

\section{References}

[1] C. D. Hepler, L. M. Strand. Opportunities and responsibilities in pharmaceutical care. American Journal of Health-System Pharmacy 1989;47(3):533-543.

[2] American Society of Hospital Pharmacists. ASHP statement on pharmaceutical care. Am J Hosp Pharm. 1993;50:1720-1723.

[3] N. Shokri, H. Akbari Javar. Patient Satisfaction with Community Pharmacies in Tehran, Iran; Part I. Iran J Public Health 2016;45(4):555557.

[4] A. Shafiee, H. Farsam. Teaching and Learning Pharmaceutical Code of Ethics as a Syllabus. Iran J Public Health 2008;37(1):47-49.

[5] M. T. Brown, J. K. Bussell. Medication Adherence: WHO Cares? Mayo Clin Proc. 2011; 86(4): 304-314.

[6] A. Kubica, M. Gruchała, M. Jaguszewski, et al. Adherence to treatment - a pivotal issue in long-term treatment of patients with cardiovascular diseases. An expert standpoint AB. Medical Research Journal 2017; 2(4):123-127.

[7] A. Miles, J. E. Asbridge. The chronic illness problem. The person-centered solution. European Journal for Person Centered Healthcare 2016;4(1):1-5.

[8] M. Morgado, S. Rolo, M. Castelo-Branco. Pharmacist intervention program to enhance hypertension control: a randomised controlled trial. Int J Clin Pharm 2011;33(1):132-140.

[9] E. Abdelhamid, A. Awad, A. Gismalla. Evaluation of a hospital pharmacy-based pharmaceutical care services for asthma patients. Pharmacy Practice 2008;6(1):25-32.

[10] C. Collins, B. L. Limone, J. M. Scholle, et al. Effect of pharmacist intervention on glycemic control in diabetes. Diabetes Res Clin Pract. 2011;92(2):145-152.

[11] A. Liekweg, M. Westfeld, B. Braun, et al. Pharmaceutical care for patients with breast and ovarian cancer. Support Care Cancer 2012;20(11):2669-2677.

[12] H. Y. Park, S. A. Seo, H. Yoo, et al. Medication adherence and beliefs about medication in elderly patients living alone with chronic diseases. Patient Prefer Adherence 2018; 12: 175-181.

[13] Report of the Central Statistical Office, Pharmacies and pharmacy outlets in 2017. https:/stat.gov.pl/obszarytematyczne/zdrowie/zdrowie/apteki-i-punkty-apteczne-w-2017-roku,15,2.html, (accessed 15 May 2020) [in Polish].

[14] [Pharmaceutical care pilot programs in Poland 2019]. https://www.nia.org.pl/2019/03/14/programy-pilotazowe-opieki-farmaceutycznejw-polsce/ (accessed 20 May 2020) [in Polish]. 
[15] D. Świeczkowski, J. Krysiński, P. Merks, et al. [Pharmaceutical care in the opinion of doctors and pharmacists of the Pomeranian Voivodeship]. Farm. Pol. 2016;72(4):201-210 [in Polish].

[16] A. Mazurek, J. Woś, J. Rowińska, et al. [Pharmaceutical care in Polish pharmacies]. Gazeta Farmaceutyczna 2016;7/8:28-29 [in Polish].

[17] J. K. Bussell, E. Cha, Y. E. Grant, et al. Ways Health Care Providers Can Promote Better Medication Adherence. Clin Diabetes 2017;35(3):171-177.

[18] Y. Hsu, C. Fang, Y. Lou, et al. 4CPS-207 Efficacy of pharmacist intervention and health education in asthma control. European Journal of Hospital Pharmacy 2018;25:A138.

[19] J. L. Pringle, A. Boyer, M. H. Conklin, et al. The Pennsylvania Project: pharmacist intervention improved medication adherence and reduced health care costs. Health Aff (Millwood) 2014;33(8): 1444-1452.

[20] D. Świeczkowski, P. Merks, M. Jaguszewski [Self-treatment with the use of medicinal products with the OTC availability category risks and benefits for patients and the health care system]. Farm Pol. 2016;72 (5):286-290 [in Polish].

[21] A. Skowron, B. Rybka [Barriers to the introduction of pharmaceutical care in Poland]. Farm. Pol. 201167(4); $217-221$ [in Polish].

[22] C. Curtain, G. M. Peterson. Review of computerized clinical decision support in community pharmacy. J Clin Pharm Ther. 2014;39(4):343-348.

[23] EM-PMR. https://www.em-pmr.pl/\#/login (accessed 5 May 2020) [in Polish].

[24] Pilotage of pharmaceutical care. http://pilotazopiekifarmaceutycznej.pl/ (accessed 5 May 2020) [in Polish].

[25] The Patient Access. www.blizejpacjenta.pl (accessed 5 May 2020) [in Polish].

[26] Direct the Patient. www.skierujpacjenta.pl(accessed 5 May 2020) [in Polish].

[27] Healthy Heart Service. www.uslugazdroweserce.pl (accessed 5 May 2020) [in Polish].

[28] Report of the Supreme Chamber of Pharmacy and the Aflofarm Foundation, Pharmacist in Poland. Nationwide image research, 2019. https://www.nia.org.pl/2019/04/11/po-pierwsze-farmaceuta-ruszyla-kampania-wizerunkowa-zawodufarmaceuty/raport farmaceuta w polsce 2019/ (accessed 25 May 2020) [in Polish].

[29] P. Merks, D. Świeczkowski, E. Blicharska, et al. [Prospects for the implementation of pharmaceutical care into pharmacy practice in the conditions of the Polish health care system]. Czasopismo Aptekarskie 2015;8-9:28-38 [in Polish].

[30] The Pharmaceutical Law of September 6, 2001 (Journal of Laws 2001, No. 126, item 1381) [in Polish].

[31] Regulation of the Minister of Health of September 26, 2002 on the list of rooms included in the primary and auxiliary areas of a pharmacy (Journal of Laws 02.161.1338) [in Polish]. 